\title{
HIV research in South Africa: Advancing life
}

G Gray, ${ }^{1,2} \mathrm{MB}$ BCh, FCPaeds (SA), DSc (Honoris causa), LLD (Honoris causa); T Doherty, ${ }^{1} \mathrm{PhD}$; L Mohapi, ${ }^{2} \mathrm{BSc}, \mathrm{MB}$ BCh; J Coetzee, ${ }^{1,2} \mathrm{PhD}$; K L Hopkins, ${ }^{2}$ MPH; M Malahleha, ${ }^{3}$ MB ChB, Dip HIV Man (SA), MPH; E Lazarus, ${ }^{2}$ MB BCh, Dip HIV Man (SA), DCH; J Dietrich, ${ }^{1,2}$ PhD; V Pillay-van Wyk, ${ }^{1} \mathrm{MPH}, \mathrm{PhD} ; \mathrm{F}$ Laher, ${ }^{2} \mathrm{MB}$ BCh, Dip HIV Man (SA)

${ }^{1}$ South African Medical Research Council, Cape Town, South Africa

${ }^{2}$ Perinatal HIV Research Unit, Faculty of Health Sciences, University of the Witwatersrand, Johannesburg, South Africa

${ }^{3}$ Setshaba Research Centre, Pretoria, South Africa

Corresponding author: G Gray (glenda.gray@mrc.ac.za)

South African (SA) researchers have made both national and global contributions to HIV prevention and treatment. Research conducted in SA has contributed markedly to improved survival in HIV-infected infants, children and adults. The translation of clinical research into practice has enabled the curtailment of paediatric HIV in SA. Along with international collaborators, SA has made pivotal contributions to biomedical prevention modalities including medical male circumcision and oral and topical microbicides, and is undertaking pivotal HIV vaccine research. Research into the structural and psychosocial drivers of HIV infection will be critical for sustaining biomedical interventions, and necessary to end AIDS.

S Afr Med J 2019;109(11 Suppl 1):36-40. https://doi.org/10.7196/SAMJ.2019.v109i11b.14264

The graph of our region's life expectancy shows a peculiar dip in the 1990s that persists for a decade. ${ }^{[1]}$ Those who were on the forefront communities and their healthcare workers - can discern the cause of that dip through personal experience. HIV/AIDS went on to devastate South Africa (SA), overwhelming a fragile healthcare system not yet repaired from the damage of apartheid, killing the young and economically active in vast numbers, spreading stigma, leaving a generation of orphans and blotting the legacy of the political regime that rubber-stamped the avoidable deaths of over 300000 South Africans by propagating AIDS denialism. By the mid-2000s, the graph begins to recover, ${ }^{[1]}$ a testament to the human effort of the health activists, researchers and healthcare workers who contributed to alleviating the health crisis of our time. SA's force of HIV researchers can point to that recovery in the graph and say, 'We had a part to play in this.'

SA, with the largest HIV epidemic in the world, estimated at 7.52 million people living with HIV, still sees too many AIDS-related deaths: 115167 people died of AIDS in 2018. ${ }^{[2]}$ Although the death toll has substantially reduced, from 283564 in $2006,{ }^{[3]}$ it is still too high for an era in which sophisticated treatments are available (Fig. 1) ${ }^{[4]} \mathrm{New}$ infections continue: the estimate of 231000 new infections in $2017^{[5]}$ is a rallying call toward strengthening preventive efforts.

Here we summarise the past, current and anticipated future contributions of HIV research in SA to help quell our epidemic.

\section{How HIV affects life and death in SA}

In 2005, the year after the public antiretroviral treatment (ART) programme had its limited launch, average life expectancy in SA reached a low point of 51.9 years for men and 55.5 for women ${ }^{[4]}$ By 2017, life expectancy was 61.2 and 67.4 years for men and women, respectively. ${ }^{[4]}$ This dramatic progress is attributed to the decline in HIVrelated mortality, specifically in young adults accessing treatment, ${ }^{[6]}$ and in infants who avoided HIV infection thanks to ART-based prevention of mother-to-child transmission (PMTCT) strategies. ${ }^{[4]}$

Among adolescents and young adults, particularly women, HIV/ AIDS has had a deadly effect in SA. The probability of a 15-year-old SA girl dying before the age of 25 was influenced by the country's response to HIV: this statistic peaked at the height of the untreated epidemic in 2004, and then significantly reduced in the era of ART availability

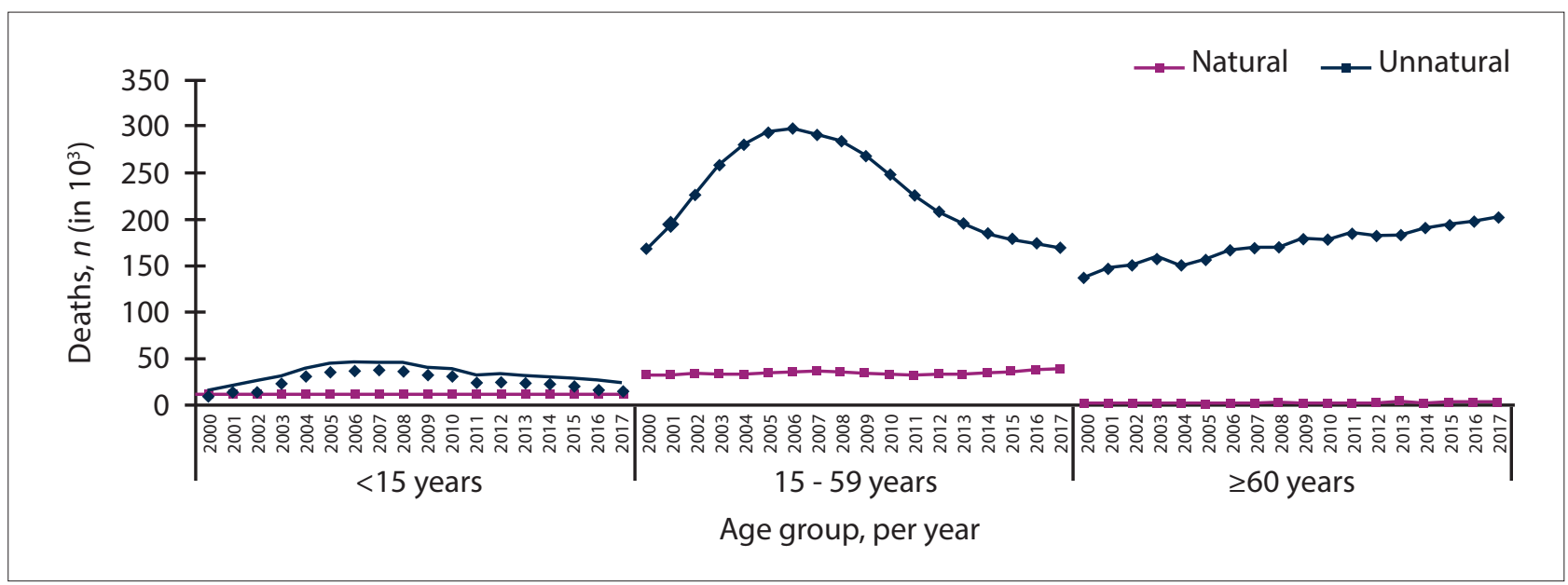

Fig. 1. Trend in the number of natural and unnatural deaths by broad age group, 2000 - 2017. (HIV-related deaths are classified as natural deaths. ${ }^{[4]}$ 
(Table 1). ${ }^{[4]}$ In parallel, infant and under-5 mortality rates are also declining in SA, and in 2017 were 23 and 32 per 1000 live births, respectively - on track to meet the 2019 targets. ${ }^{[4]}$

\section{Changing the trajectory of the HIV epidemic through research and implementation of ART}

In 2004, SA launched what has since grown into the largest ART programme on the planet. ${ }^{[5]}$ During this time, there have been significant advances in treatment science, which have been adopted in programmatic implementation. Key examples of the country's research-to-implementation model informing the success of the ART programme include (i) ART initiation eligibility for children and adults; ${ }^{[7,8]}$ and (ii) task-shifting from an elite subset of 'HIV doctors' to HIV-trained nurses. ${ }^{[9,10]}$

Discovery of improved strategies for determining eligibility for ART initiation, and their implementation

Conducted in SA during a time when children had to meet steep immunological, virological and clinical criteria to start ART, ${ }^{[11]}$ the Children with HIV Early Antiretroviral Therapy (CHER) study had startling findings: early HIV diagnosis and ART initiation reduced early infant mortality by $76 \%$, and HIV progression by $75 \%{ }^{[7]}$ The study influenced local and international clinical guidelines to treat children at diagnosis, translating into improved paediatric HIV outcomes globally. ${ }^{[11,12]}$

SA researchers also contributed to a study that influenced the change in adult treatment eligibility guidelines. The Strategic Timing of Antiretroviral Treatment (START) study, conducted in 35 countries including SA, showed that immediate ART initiation at CD4+ counts $>500$ cells $/ \mu \mathrm{L}$ was superior to deferring ART initiation until the CD4+ count was $<350$ cells $/ \mu \mathrm{L}^{[8]}$

SA researchers, faced with a significant HIV/TB comorbidity problem, provided evidence for the timing of ART initiation after TB treatment. ART initiation within 4 weeks of TB treatment increased AIDS-free survival for patients with $\mathrm{CD} 4+$ counts $<50$ cells $/ \mu \mathrm{L}$. However, ART initiation ought to be deferred to the first 4 weeks of the continuation phase of TB treatment in those with higher CD4+ T-helper cell counts. ${ }^{[13,14]}$

The newest SA guidelines recommend a first-line dolutegravirbased regimen to replace the efavirenz component, minimising the side-effect profile and prolonging durable virological suppression. ${ }^{[15]}$ Studies researching further ART regimen optimisation include WRHI $052,{ }^{[16]}$ which suggests that switching from a ritonavir-boosted lopinavir nucleoside-analogue-based regimen to a daily low-dose ritonavir-boosted darunavir nucleoside-analogue-based regimen after viral suppression might be safe and efficacious. The ADVANCE study is investigating a candidate universal ART regimen, including the replacement of tenofovir disoproxyl fumarate with tenofovir

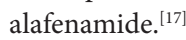

\footnotetext{
The evidence of good outcomes with task-shifting opens the way for ART scale-up

Researchers in SA conducted two landmark studies on taskshifting, one through the Comprehensive International Program for Research in AIDS in SA (CIPRA SA), and the other called the Streamlining Tasks and Roles to Expand Treatment and Care for HIV (STRETCH) study. Both proved that task-shifting was not deleterious to patient outcomes, thereby facilitating the scale-up of the SA ART programme to reach the millions of people living with HIV needing treatment initiation and lifelong monitoring. ${ }^{[9,10]}$
}

Table 1. Probability per 1000 of a 15 -year-old SA female dying before age 25 years $^{[4]}$

\begin{tabular}{ll}
\hline Year & Probability \\
\hline 2000 & 35.1 \\
2004 & 44.4 \\
2017 & 17.0 \\
SA $=$ South African. &
\end{tabular}

\section{PMTCT: The SA commitment to protecting babies and mothers}

SA has been at the forefront of PMTCT research. As evidence mounted from research in high-income settings about the effectiveness of ART for PMTCT, scientists in SA sought to determine whether such regimens were feasible for wide-scale implementation in low- and middle-income health-system contexts with breastfeeding populations. The multicountry PErinatal TRAnsmission (PETRA) trial (1996 - 2000) ${ }^{[18]}$ which included two SA sites, assessed the efficacy of three different short-course antiretroviral (ARV) regimens. The PETRA trial showed that shortcourse ARV regimens effectively reduced intrapartum transmission, but that additional measures were needed to prevent postnatal breastmilk transmission. ${ }^{[18]}$ After maternal-infant administration of singledose nevirapine (sdNVP) was found to be moderately efficacious and affordable, SA scientists designed the South African Intrapartum Nevirapine Trial (SAINT) to evaluate whether an additional maternal dose of NVP could further reduce transmission rates. The trial demonstrated the efficacy of two inexpensive regimens given during labour in reducing intrapartum and early postpartum transmission. ${ }^{[19]}$ However, the two maternal doses of NVP were found to increase the prevalence of NVP resistance. Given the high rates of non-nucleoside reverse-transcriptase inhibitor (NNRTI)-resistance mutations in most women and HIV-infected infants receiving NVP, including sdNVP, a study to assess adding a short course of zidovudine (AZT) and lamivudine (3TC) was designed and conducted in SA. This intervention was found to reduce emergent resistant mutations in both mothers and their infants, and was incorporated into clinical care. ${ }^{[20]}$

After the demonstration of short-course antiretroviral therapy for PMTCT, the WHO published technical notes on PMTCT stating that 'there was no longer any justification to restrict use of any of these regimens to pilot project or research settings. ${ }^{[21]}$ Following a Constitutional Court battle against the National Department of Health $(\mathrm{NDoH})$ by the Treatment Action Campaign, the SA government began, in 2003, to scale up an NVP-based PMTCT programme from two pilot sites per province to reach national coverage. ${ }^{[22]}$ Although early MTCT rates declined after the scale-up of single and short-course regimens in SA, the challenge remained as to how to prevent postnatal transmission through breastmilk, and how to improve maternal health. ${ }^{[23,24]}$ Researchers in Soweto evaluated the role of post-exposure prophylaxis in preventing post-partum transmission, which led to the multi-centre HPTN 040 trial. This trial assessed three post-partum interventions to prevent HIV transmission ${ }^{[25]}$ and changed clinical guidelines for post-partum prophylaxis for HIVexposed infants whose mothers had been undiagnosed during pregnancy and labour. ${ }^{[26]}$

Research undertaken in SA, one of only a few African countries that provided free formula milk to HIV-infected mothers, provided evidence regarding HIV outcomes related to infant feeding choices. ${ }^{[27,28]}$ A study conducted in KwaZulu-Natal Province found that exclusive breastfeeding carried a significantly lower risk of HIV-1 transmission than mixed feeding, and a similar risk to exclusive formula feeding. ${ }^{[29]}$ These findings were confirmed in another study at the rurally-located Africa Centre, which also documented higher mortality among infants given replacement feeds compared with those exclusively 
breastfed. ${ }^{[30]}$ These two studies guided the 2009 WHO recommendations on HIV and infant feeding towards exclusive breastfeeding for 6 months, and continued breastfeeding until 12 months old, together with ART. ${ }^{[2,31]}$

PROMISE (2011 - 2015), a landmark multi-country trial that included sites in SA, investigated the benefits and risks of combination ART given to pregnant women with a $\mathrm{CD} 4+$ count of at least 350 cells $/ \mu \mathrm{L}$ compared with short-course AZT and sdNVP. PROMISE proved that antenatal ART resulted in significantly lower rates of early HIV transmission than zidovudine alone ${ }^{[32]}$ which led to the decision by the SA government in 2015 to recommend starting lifelong ART for pregnant HIV-positive women, irrespective of $\mathrm{CD} 4+$ count. These evidence-informed policy changes led to dramatic improvements in the health and survival of women and children, such that by 2015, HIV was no longer the leading cause of under- 5 deaths, and had declined significantly as a contributor to maternal deaths. ${ }^{[33]}$ These successes have created an important area for current research, namely the health of HIVexposed uninfected children, the focus of another article in this supplement. ${ }^{[34]}$

SA scientists have also contributed important health-systems research, undertaken across the continent, regarding strategies to improve the implementation of PMTCT policies in primary healthcare settings, ${ }^{[35-37]}$ and the role of community cadres in strengthening linkages between households and health facilities. ${ }^{[38,39]}$

Future research in SA will be aimed at reducing the residual risk of breastmilk transmission, possibly including novel interventions such as passive immunisation with broadly neutralising antibodies or active vaccination strategies.

\section{HIV prevention research and interventions in SA}

From 2011 to 2016, there has been a 34\% decrease in new HIV infections among 15 - 49-year-olds in SA. ${ }^{[40]}$ Contributors to the decline include: $(i)$ increased ART uptake; ${ }^{[41]}$ (ii) the scale-up of voluntary medical male

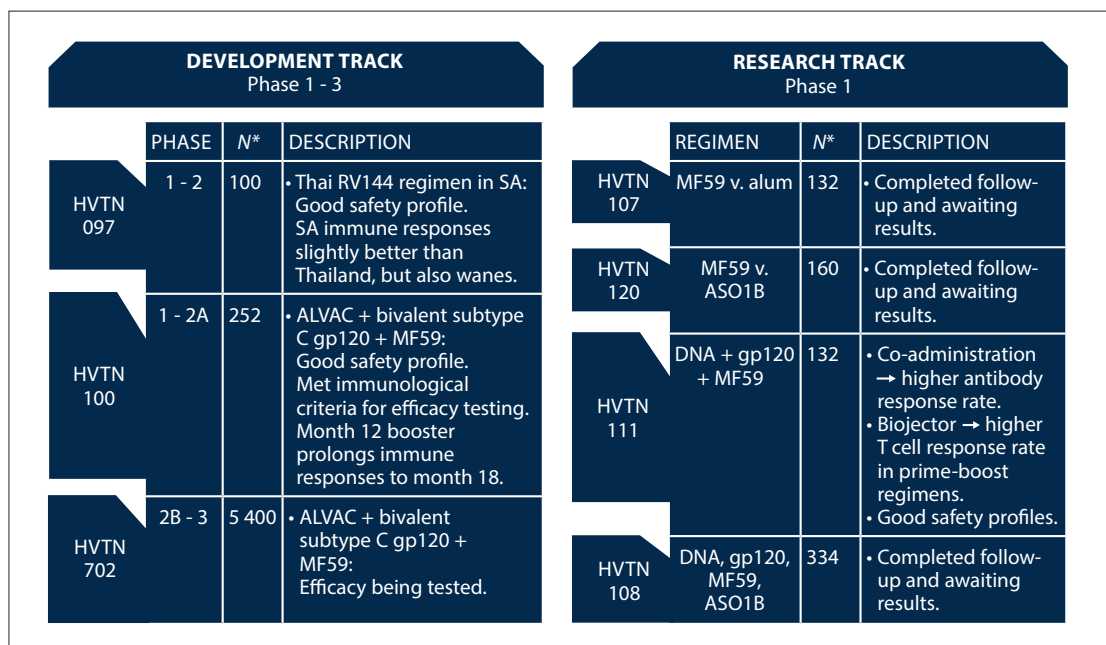

Fig. 2. Study tracks of the Pox-Protein Public-Private Partnership (P5), which is investigating vaccines against HIV clade C (the South African Medical Research Council is one of the P5 partners $).(S A=$ South Africa. $){ }^{\star}$ Participants.

circumcision to 2.4 million procedures conducted between 2012 and 2016 alone; ${ }^{[40]}$ (iii) increased condom distribution; ${ }^{[40,41]}$ and (iv) increased availability of HIV testing services at over 4500 public healthcare facilities, which tested 13 million South Africans within 18 months. ${ }^{[2,43]}$ SA has contributed much research evidence on HIV prevention, including the protective effects of medical male circumcision on male HIV acquisition, ${ }^{[4]}$ treatment of people living with HIV as prevention to HIV-uninfected partners ${ }^{[45]}$ and the proven lack of efficacy of the diaphragm in preventing HIV acquisition. ${ }^{[46]}$

In 2016, SA began the rollout of preexposure prophylaxis (PrEP) to sex workers. ${ }^{[47]}$ PrEP services were extended to men who have sex with men (MSM) and to adolescent girls and young women between 2018 and 2019, ${ }^{[40]}$ with plans for provision to postpartum women, and for high-transmission areas. The effectiveness of oral and topical PrEP, which is closely tied to adherence, has varied across studies conducted in different populations. Generally, oral PrEP effectiveness has been high among MSM in high-income countries. ${ }^{[48,49]}$ Studies conducted among women in SA have yielded different results. The effectiveness of oral Truvada as PrEP has ranged between $-4 \%$ $(\mathrm{VOICE})^{[50]}$ and $6 \%$ (FEMPREP $^{[51]}$ in African trials, and poor adherence has been implicated. ${ }^{[50,51]}$ The effectiveness of topical tenofovir gel microbicide, an SA initiative, ranged between 0\% (FACTS 001), ${ }^{[52]} 15 \%$ $\left(\right.$ VOICE) ${ }^{[50]}$ and $39 \%$ (CAPRISA 004). ${ }^{[53]}$ Again, poor adherence was implicated. Such findings, shown in Table 2, highlight the ongoing need for a regionally acceptable method of HIV prevention, especially for young women in Africa, who are a mostat-risk population for HIV acquisition. The ASPIRE and RING trials found that the intravaginal dapivirine ring had modest efficacies of $27 \%$ and $31 \%$, respectively. ${ }^{[5,55]}$

Table 2. Summary of ARV-based PrEP trials in SA showing low to modest efficacy

\begin{tabular}{lllll}
\hline Prevention trial & Trial & Trial & Participants & $\begin{array}{l}\text { Effectiveness, } \\
\text { name }\end{array}$ \\
\hline Topical tenofovir gel, coital & CAPRISA 004 & SA & Women & 39 \\
& FACTS 001 & SA & Women & 0 \\
Topical tenofovir gel, daily & MTN003/VOICE & SA, Uganda, Zimbabwe & Women & 15 \\
Oral Truvada, daily & iPrex & Americas, Thailand, SA & MSM/transgender & 44 \\
& FeMPrEP & Kenya, SA, Tanzania & Women & 6 \\
Oral tenofovir, daily & MTN003/VOICE & SA, Uganda, Zimbabwe & Women & -4 \\
Dapivirine ring & MTN003/VOICE & SA, Uganda, Zimbabwe & Women & -49 \\
& RING & SA, Uganda & Women & $31(0$ in $18-21$ yrs $)$ \\
& ASPIRE/MTN020 & Malawi, SA, Uganda, Zimbabwe Women & $27(0$ in $18-21$ yrs $)$
\end{tabular}

$\mathrm{ARV}=$ antiretroviral; $\mathrm{PrEP}=$ pre-exposure prophylaxis; $\mathrm{SA}=$ South Africa; $\mathrm{MSM}=$ men who have sex with men 


\section{SA contributions to the search for a preventive $H I V-1$ vaccine}

SA has adopted multiple HIV prevention tools into the public health system, including barrier methods, male medical circumcision and ARV prophylaxis strategies. ${ }^{[56]}$ However, new infections continue to amass. ${ }^{[5]}$ The challenges of current HIV prevention methods include resource constraints, reliance on daily adherence, patriarchal power imbalances and method unsuitability for women - the sex that experiences disproportionate infection risk. ${ }^{[57]}$ As with other pathogens, a vaccine could cost-effectively deliver us to a tipping point in HIV control. ${ }^{[58,59]}$

For over 18 years, SA has contributed to the pursuit of a preventive HIV vaccine. ${ }^{[57]}$ In collaboration with community, local and international stakeholders, the SA Medical Research Council (SAMRC), through the SA AIDS Vaccine Initiative (SAAVI), has pioneered studies of vaccines against the clade C HIV subtype responsible for the highest number of global HIV infections, such as the SAAVI-developed DNA.C and recombinant MVA vaccines. ${ }^{[60,61]}$ The SAMRC-led SAAVI programme was a public-private partnership funded by the NDoH, Department of Science and Technology and Eskom, which, after a 9-year development period, created a pipeline of candidate HIV-1 subtype $\mathrm{C}$ vaccines. These included virus-like particles, novel DNA plasmid vaccines, capripoxvirus and Bacillus Calmette-Guérin (BCG)-vectored vaccines. ${ }^{[62]}$

The research of an HIV vaccine has required much persistence. In the evaluation of the MRK-Ad5 HIV vaccine, the SA HVTN 503/ Phambili trial was stopped early after the declaration of futility of its companion study in the Americas, the HVTN 502/Step trial. A finding that halted further Adenovirus 5 platform development was that MRKAd5 increased the susceptibility to HIV in male volunteers, irrespective of circumcision and Ad5 serostatus. ${ }^{[63,64]}$

Since the 2009 milestone announcement in Thailand of the first vaccine regimen with some efficacy, ${ }^{[65]}$ the SAMRC, as part of the Pox-Protein Public-Private Partnership, has collaborated in the development of a similar heterologous prime-boost regimen for clade C (Fig. 2). When South Africans were vaccinated with the Thai regimen, the initially robust cross-clade immune responses were not durable ${ }^{[66]}$ However, the addition of a booster to the clade-C adapted regimen prolonged immune responses. ${ }^{[67]}$ The latter regimen has progressed to an efficacy trial, HVTN $702 /$ Uhambo, ${ }^{[6]}$ which is chaired by four female SA medical researchers. HVTN 702/Uhambo completed enrollment in July 2019 at its 14 SA sites. In parallel, results of other vaccine trials show that replacing the pox vector with a DNA plasmid vaccine prime can also induce relevant immune responses. The potential for easy and cheap manufacturing of DNA plasmid vaccines makes this avenue promising. ${ }^{[68]}$

SA researchers are also contributing to the clinical development of a global antigen HIV vaccine. An early-phase trial of a prime-boost vaccine strategy evaluating a mosaic adenovirus- 26 vector and clade C gp140 protein conducted across three continents (Africa, Asia and North America) produced robust immune responses, comparable with those found to be efficacious in preclinical studies. ${ }^{[69]}$ These findings led to the implementation of the HVTN 705/VAC89220HPX2008/Imbokodo phase $2 \mathrm{~b}$ efficacy trial currently underway in sub-Saharan Africa (SSA), including 17 SA sites. ${ }^{[70}$

Passive immunisation with monoclonal antibodies $(\mathrm{mAb})$ is another promising strategy that has been shown to be protective in preclinical studies. ${ }^{[71,72]}$ The first phase $2 \mathrm{~b}$ human trial investigating preventive efficacy of the VRC01 $\mathrm{mAb}$ is underway in SSA. SA scientists have also identified a neutralising antibody, CAP256, which is highly potent against clade C HIV, and about to enter early clinical development. ${ }^{[73,74]}$

\section{Future focus of research}

We still need to find solutions to the underlying structural, psychosocial and behavioural drivers of the HIV epidemic. Key to epidemic control will be the engagement of young people and key populations such as sex workers, their clients and MSM, to ensure the uptake of biomedical interventions as well as address issues of intimate partner violence, intergenerational sex and patriarchy. ${ }^{[75-85]}$ SA research has exposed gender-based violence as a key driver of HIV acquisition. ${ }^{[81]}$ Gender-based violence is endemic across SA, driving mental health concerns, ${ }^{[75,84-86]}$ both of which are associated with poor health-seeking behaviours and poor adherence to medications. ${ }^{[87-90]}$

Attention to designing interventions that ensure access to HIV prevention, treatment and care for adolescent girls and young adults may contribute to breaking the transmission cycle. Future research should also focus on understanding the HIV epidemic in men, and factors associated with transmission, such as intergenerational and transactional sexual partnerships.

\section{Conclusion}

The small community of SA researchers, supported by their communities, study participants, collaborations and sponsors, has made key scientific contributions that inform public programmes on changing the course of the HIV epidemic, and improving public health.

Acknowledgements. We thank researchers, study participants, collaborators, communities and community activists for their efforts to curtail the HIV epidemic in SA.

Author contributions. Equal contributions.

Funding. The South African Medical Research Council funded time for GG, TD and JC. JC's time was also funded by the Wellcome Trust.

Conflicts of interest. None.

The World Bank. Life expectancy at birth, total (years) - South Africa. https://data.worldbank.org/ indicator/SP.DYN.LE00.IN?locations=ZA (accessed 15 June 2019).

Statistics South Africa. Mid-year population estimates, 2018. Pretoria: StatsSA, 2018. http://www. statssa.gov.za/?p=11341 (accessed 15 June 2019)

Pillay-van Wyk V, Msemburi W, Dorrington RE, et al. HIV/AIDS mortality trends pre- and post-ART for 1997 - 2012 in South Africa - have we turned the tide? S Afr Med J 2019;109(11 Suppl 1):41-44. https://doi.org/10.7196/SAMJ.2019.v109i1lb.14283

Dorrington R, Bradshaw D, Laubscher R, Nannan N, Burden of Disease Research Unit. Rapid mortality surveillance report 2017. Cape Town: South African Medical Research Council, 2019. 5oint United Nations Programme on HIV/AIDS. UNAIDS Data 2018. https://www.unaids.org/sites/ default/files/media_asset/unaids-data-2018_en.pdf (accessed 29 October 2019).

Shisana O, Rehle T, Simbayi L, et al. South African National HIV Prevalence, Incidence, Behaviour and Communication Survey 2008: A Turning Tide Among Teenagers? Cape Town: HSRC Press, 2009. Violari ACM, Gibb DM, Babiker AG, et al. Early anting Teenagers? Cape Town: HSRC Press, 2009. 7. Violari ACM, Gibb DM, Babiker AG, et al. Early antiretroviral therapy and mortality among HIV infected infants. New Engl J Med 2013;359(21):2233-2244. https://doi.org/ 10.1056/NEJMoa080097 INSIGHT START Study Group, Lundgren JD, Babiker AG, et al. Initiation of antiretroviral therapy in early asymptom

9. Fairall L, Bachmann MO, Lombard C, et al. Task shifting of antiretroviral treatment from doctors to primary-care nurses in South Africa (STRETCH): A pragmatic, parallel, cluster-randomised trial. to primary-care nurses in South Africa (STRETCH): A pragmatic, parallel, clus

10. Sanne I, Orrell C, Fox MP, et al. Nurse versus doctor management of HIV-infected patients receiving . Sanne I, Orrell C, Fox MP, et al. Nurse versus doctor management of HIV-infected patients receiving
antiretroviral therapy (CIPRA-SA): A randomised non-inferiority trial. Lancet 2010;376(9734):33-40. antiretroviral therapy (CIPRA-SA): A randomised https://doi.org/10.1016/S0140-6736(10)60894-X

11. World Health Organization. Antiretroviral therapy of HIV infection in infants and children: Towards universal access: recommendations for a public health approach-2010 revision. Geneva: WHO, 2010. 12. Joint United Nations Programme on HIV/AIDS. Start free stay free AIDS free - 2019 report. Geneva: UNAIDS, 2019

13. Abdool Karim S, Naidoo K, Grobler A, et al. Timing of initiation of antiretroviral drugs during tuberculosis therapy. New Engl J Med 2010;362(8):697-706. https://doi.org/10.1056\%2FNEJMoa0905848 4. Abdool Karim SS, Naidoo K, Grobler A, et al. Integration of antiretroviral therapy with tuberculosis treatment. New Engl J Med 2011;365(16):1492-1501. https://doi.org/ 10.1056/NEJMoa1014181

15. National Department of Health, South Africa. 2019 ART Clinical guidelines for the management of $\mathrm{HIV}$ in adults, pregnancy, adolescents, children, infants and neonates. Pretoria: $\mathrm{NDoH}, 2019$.

16. Venter WDF, Sokhela S, Serenata C, et al. Low-dose ritonavir-boosted darunavir once daily v. ritonavir-boosted lopinavir for participants with less than 50 HIV RNA copies per mL (WRHI 052): A randomised, open-label, phase 3, non-inferiority trial. Lancet HIV 2019;6(7):PE428-E437. https://doi. org/10.1016/S2352-3018(19)30081-5

17. Venter WDF, Clayden P, Serenata C, OPTIMIZE Consortium. The ADVANCE study: A groundbreaking trial to evaluate a candidate universal antiretroviral regimen. Current Opin HIV AIDS 2017;12(4):351354. https://doi.org/10.1097/COH.000000000000038

18. PETRA Study Team. Efficacy of three short-course regimens of zidovudine and lamivudine in preventing early and late transmission of HIV-1 from mother to child in Tanzania, South Africa and Uganda (PETRA 2002:359(9313):1178-1186. hitps/10iolo 
19. Moodley D, Moodley J, Coovadia H, et al. A multicenter randomised controlled trial of nevirapine v a combination of zidovudine and lamivudine to reduce intrapartum and early postpartum motherto-child transmission of Human Immunodeficiency Virus Type 1. J Infect Dis 2003;187(5):725-735. to-child transmission of Human
https://doi.org/10.1086/367898

20. McIntyre JA, Hopley M, Moodley D, et al. Efficacy of short-course AZT plus 3TC to reduce nevirapine resistance in the prevention of mother-to-child HIV transmission: A randomised clinical trial. PLoS resistance in the prevention of mother-to-child HIV transmission: A ran
Med 2009;6(10):e1000172. https://doi.org/10.1371/journal.pmed.1000172

21. World Health Organization. Prevention of mother to child transmission of HIV: Selection and use of nevirapine technical notes. Geneva: WHO, 2001

22. McCoy D, Besser M, Visser R, Doherty T, Nicholson J. Interim findings on the National PMTCT pilot sites. Summary of lessons and recommendations. Durban: Health Systems Trust, 2002.

23. Colvin M, Chopra M, Doherty T, et al. Operational effectiveness of single-dose nevirapine in preventing mother-to-child transmission of HIV. Bull World Health Organ 2007;85(6):466-473. https://doi.org/10.2471/blt.06.033639

24. Goga AE, Jackson DJ, Singh M, Lombard C, SAPMTCTE study group. Early (4 - 8 weeks post-delivery) population-level effectiveness of WHO PMTCT option A, South Africa, 2012 - 2013. Pretoria: South African Medical Research Council and National Department of Health, 2014.

25. Nielsen-Saines K, Watts DH, Veloso VG, et al. Three postpartum antiretroviral regimens to prevent intrapartum HIV infection. New Engl J Med 2012;366(25):2368-2379. https://doi.org/10.1056/ NEJMoa1108275

26. National Department of Health, South Africa. The South African antiretroviral treatment guidelines 2013. Pretoria: $\mathrm{NDoH}, 2013$

27. Arikawa S, Rollins N, Jourdain G, et al. Contribution of maternal antiretroviral therapy and breastfeeding to 24-month survival in human immunodeficiency virus-exposed uninfected children: An individual pooled analysis of African And Asian studies. Clin Infect Dis 2018;66(11):1668-1677. https://doi.org/10.1093/cid/cix1102

28. Venkatesh KK, de Bruyn G, Marinda E, et al. Morbidity and mortality among infants born to HIVinfected women in South Africa: Implications for child health in resource-limited settings. J Trop Pediatr 2011;57(2):109-119. https://doi.org/10.1093\%2Ftropej\%2Ffmq061

29. Coutsoudis A, Pillay K, Spooner E, Kuhn L, Coovadia HM. Influence of infant-feeding patterns on early mother-to-child transmission of HIV-1 in Durban, South Africa: A prospective cohort study. South African Vitamin A Study Group. Lancet 1999;354(9177):471-476. https://doi.org/10.1016/ South African Vitamin
s0140-6736(99)01101-0

30. Coovadia HM, Rollins NC, Bland RM, et al. Mother-to-child transmission of HIV-1 infection during exclusive breastfeeding in the first 6 months of life: An intervention cohort study. Lancet during exclusive breastfeeding in the first 6 months of life: An intervent
2007;369(9567):1107-1116. https://doi.org/10.1016/S0140-6736(07)60283-9

31. World Health Organization. HIV and infant feeding. Revised principles and recommendations. Rapid advice. Geneva: WHO, 2009

32. Fowler MG, Qin M, Fiscus SA, et al. Benefits and risks of antiretroviral therapy for perinatal HIV prevention. New Engl J Med 2016;375(18):1726-1737. https//doi.org/ 10.1056/NEJMoa1511691

33. United Nations International Children's Emergency Fund. Countdown to 2015 maternal newborn
and child survival: A decade of tracking progress for maternal, newborn and child survival: The 2015 Report. New York: UNICEF, 2015

34. Goga A, Slogrove A, Wedderburn CJ, et al. The impact of health programmes to prevent vertical transmission of HIV: Advances, emerging health challenges and research priorities for children exposed to or living with HIV. S Afr Med J 2019;109(11 Suppl 1):77-82. https://doi.org/10.7196/ SAMJ.2019.v109i11b.14292

35. Besada D, Rohde S, Goga A, et al. Strategies to improve male involvement in PMTCT Option B+ in four African countries: A qualitative rapid appraisal. Global Health Act 2016;9(1):33507. https://doi. org/10.3402\%2Fgha.v9.33507

36. Horwood C, Haskins L, Vermaak K, Phakathi S, Subbaye R, Doherty T. Prevention of mother-to-child transmission of HIV (PMTCT) programme in KwaZulu-Natal, South Africa: An evaluation of PMTCT implementation and integration into routine maternal, child and women's health services. Trop Med Int Health 2010;15(9):992-999. https://doi.org/10.1111/j.1365-3156.2010.02576.x

37. Doherty T, Chopra M, Nsibande D, Mngoma D. Improving the coverage of the PMTCT programme through a participatory quality improvement intervention in South Africa. BMC Public Health 2009;9:406. https://doi.org/10.1186/1471-2458-9-406

38. Besada D, Goga A, Daviaud E, Rohde S, Chinkonde JR, Villeneuve S, et al. Roles played by community cadres to support retention in PMTCT Option B+ in four African countries: A qualitative rapid appraisal. BMJ Open 2018;8(3):e020754. http://doi.org/10.1136/bmjopen-2017-020754

39. Tomlinson M, Doherty T, Ijumba P, et al. Goodstart: A cluster randomised effectiveness trial of an integrated, community-based package for maternal and newborn care, with prevention of motherintegrated, community-based package for maternal and newborn care, with prevention of mother-
to-child transmission of HIV in a South African township. Trop Med Int Health 2014;19(3):256-266. to-child transmission of HIV in a
https://doi.org/10.1111/tmi.12257

40. South African National AIDS Council. South Africa’s National Strategic Plan for HIV, TB and STIs South African National AIDS Coun
2017 - 2022. Pretoria: SANAC, 2017 .

41. Williams BG, Gupta S, Wollmers MRG. Progress and prospects for the control of HIV and tuberculosis Williams BG, Gupta S, Wollmers MRG. Progress and prospects for the control of HIV and tuberculosis
in South Africa: A dynamic modelling study. Lancet Public Health 2017;2(5):223-230. https://doi. org/10.1016/S2468-2667(17)30066-X

42. Mohlabane N, Tutshana B, Peltzer KAM. Barriers and facilitators associated with HIV testing uptake in South African health facilities offering HIV counselling and testing. Health SA Gesondheid 2015;21(2016):86-95. https://doi.org/10.1016/j.hsag.2015.11.001

43. National Department of Health, South Africa. National HIV testing services: Policy and guidelines 2015. Pretoria: $\mathrm{NDoH}, 2015$

44. Mahiane SG, Legeai C, Taljaard D, et al. Transmission probabilities of HIV and herpes simplex virus type 2, effect of male circumcision and interaction: A longitudinal study in a township of South Africa. AIDS 2009;23(3):377-383. https://doi.org/10.1097/qad.0b013e32831c5497

45. Cohen MS, Chen YQ, McCauley M, et al. Antiretroviral therapy for the prevention of HIV-1 transmission. New Engl J Med 2016;375(9):830-839. https://doi.org/10.1056/NEJMoal600693

46. Padian NS, van der Straten A, Ramjee G, et al. Diaphragm and lubricant gel for prevention of HIV acquisition in southern African women: A randomised controlled trial. Lancet 2007;370(9583):251261. https://doi.org/10.1016/S0140-6736(07)60950-7

47. South African National AIDS Council. South African national sex worker HIV plan, 2016 - 2019. Pretoria: SANAC, 2016.

48. Hood JE, Buskin SE, Dombrowski JC, et al. Dramatic increase in pre-exposure prophylaxis use among MSM in Washington state. AIDS 2016;30(3):515-519. https:///doi.org/10.1097/QAD.0000000000000937

49. Kessler J, Myers JE, Nucifora KA, et al. Evaluating the impact of prioritisation of antiretroviral preexposure prophylaxis in New York. AIDS 2014;28(18):2683-2691. https://doi.org/10.1097\%2FQ AD. 0000000000000460

50. Marrazzo J. Pre-exposure prophylaxis for HIV in women: Daily oral tenofovir, oral tenofovir/ emtricitabine or vaginal tenofovir gel in the VOICE study (MTN 003). 20th Conference on Retroviruses emtricitabine or vaginal tenofovir gel in the VOICE study (MTN 003 ). 20th Conference on Retroviruses
and Opportunistic Infections (CROI 2013). Atlanta, 2013. https://doi.org/10.1056/NEJMoal 402269

51. Van Damme L, Corneli A, Ahmed K, et al. Pre-exposure prophylaxis for HIV infection among African Van Damme L, Corneli A, Ahmed K, et al. Pre-exposure prophylaxis for HIV infection
women. N Engl J Med 2012;367(5):411-422. https://doi.org/10.1056/NEJMoal202614

52. Delany-Moretlwe S, Lombard C, Baron D, et al. Tenofovir 1\% vaginal gel for prevention of HIV-1 infection in women in South Africa (FACTS-001): A phase 3, randomised, double-blind, placebo-
ind infection in women in South Africa (FACTS-001): A phase 3, randomised, double-blind, placebo-
controlled trial. Lancet Infect Dis 2018;18(11):1241-1250. https://doi.org/10.1016/S1473controlled trial.
$3099(18) 30428-6$

53. Abdool Karim Q, Abdool Karim SS, et al. Effectiveness and safety of tenofovir gel, an antiretroviral microbicide, for the prevention of HIV infection in women. Science 2010;329(5996):1168-1174. https://doi.org/10.1126/science.1193748
54. Baeten JM, Palanee-Phillips T, Brown ER, et al. Use of a vaginal ring containing dapivirine for HIV-1 prevention in women. New Engl J Med 2016;375(22):2121-2132. https://doi.org/10.1056/ NEJMoal506110

55. Nel A, van Niekerk N, Kapiga S, et al. Safety and efficacy of a dapivirine vaginal ring for HIV prevention in women. New Engl J Med 2016;375(22):2133-2143. https://doi.org/10.1056/NEJMoal602046

6. National Department of Health, South Africa. Health Sector HIV Prevention 2016. Pretoria: NDoH, 2016

57. Bekker LG, Gray GE. Hope for HIV control in southern Africa: The continued quest for a vaccine PLoS Med 2017;14(2):e1002241. https://doi.org/10.1371\%2Fjournal.pmed.1002241

58. Moodley N, Gray G, Bertram M. The price of prevention: Cost-effectiveness of biomedical HIV prevention strategies in South Africa. Clin Res HIV/AIDS 2016;3(1):1031.

9. Gray GE, Laher F, Doherty T, et al. Which new health technologies do we need to achieve an end to HIV/AIDS? PLoS Biol 2016;14(3):e1002372. https://doi.org/10.1371\%2Fjournal.pbio.1002372

60. Churchyard G, Mlisana K, Karuna S, et al. Sequential immunisation with gp140 boosts immune responses primed by modified vaccinia Ankara or DNA in HIV-uninfected South African participants. PloS One 2016;11(9):e0161753. https://doi.org/10.1371/journal.pone.0161753

61. Gray GE, Mayer KH, Elizaga ML, et al. Subtype C gp 140 vaccine boosts immune responses primed by the South African AIDS Vaccine Initiative DNA-C2 and MVA-C HIV vaccines after more than a 2-year the South African AIDS Vaccine Initiative DNA-C2 and MVA-C HIV vaccines after m
gap. Clin Vacc Immunol 2016;23(6):496-506. https://doi.org/10.1128/CVI.00717-15

62. Williamson AL, Rybiki E, Shephard E, et al. South African HIV-1 vaccine candidates - the journey from the bench to clinical trials. S Afr Med J 2012;102(6):452-455.

63. Gray GE, Moodie Z, Metch B, et al. Recombinant adenovirus type $5 \mathrm{HIV} \mathrm{gag} / \mathrm{pol} /$ nef vaccine in South Africa: Unblinded, long-term follow-up of the phase $2 \mathrm{~b}$ HVTN 503/Phambili study. Lancet Infect Dis 2014;14(5):388-396. https://doi.org/10.1016/S1473-3099(14)70020-9

64. Gray GE, Allen M, Moodie Z, et al. Safety and efficacy of the HVTN 503/Phambili study of a clade-Bbased HIV-1 vaccine in South Africa: A double-blind, randomised, placebo-controlled test-of-concept phase 2b study. Lancet Infect Dis 2011;11(7):507-515. https://doi.org/10.1016/S1473-3099(11)70098-6 65. Rerks-Ngarm S, Pitisuttithum P, Nitayaphan S, et al. Vaccination with ALVAC and AIDSVAX to prevent HIV-1 infection in Thailand. New Engl Med J 2009;361(23):2209-2220. https://doi. org/10.1056/NEJMoa0908492

66. Gray GE, Huang Y, Grunenberg N, et al. Immune correlates of theThai RV 144 HIV vaccine regimen in South Africa. Sci Transl Med 2019;11(510). https://doi.org/10.1126/scitranslmed.aax 1880 .

67. Bekker LG, Moodie Z, Grunenberg N, et al. A phase 1/2 HIV-1 vaccine trial of a Subtype C ALVACHIV and Bivalent Subtype C gp120/MF59 vaccine regimen in low-risk HIV-uninfected South African adults. Lancet HIV 2018;5(7):e366-e378. https:/// doi.org/10.1016/\$2352-3018(18)30071-7

68. Moodie Z, Innes C, Hosseinipour M, et al. DNA-prime induces higher magnitude humoral responses than alvac-prime in HIV vaccine regimens with the same protein boost. HIVR4P Conference. Spain, 2018.

69. Barouch DH, Tomaka FL, Wegmann F, et al. Evaluation of a mosaic HIV-1 vaccine in a multicentre, randomised, double-blind, placebo-controlled, phase 1/2a clinical trial (APPROACH) and in rhesus monkeys (NHP 13-19). Lancet 2018;392(10143):232-243. https://doi.org/10.1016/S01406736(18)31364-3

70. Imbokodo. STAND UP TO HIV! https://www.imbokodo.org.za (accessed 29 October 2019).

71. Shingai M, Donau OK, Plishka RJ, et al. Passive transfer of modest titers of potent and broadly neutralising anti-HIV monoclonal antibodies block SHIV infection in macaques. J Experiment Med 2014;211(10):2061-2074. https://doi.org/10.1084/jem.20132494

72. Hessell AJ, Poignard P, Hunter M, et al. Effective, low-titer antibody protection against low-dose repeated

73. Moldt B, Rakasz EG, Schultz N, et al. Highly potent HIV-specific antibody neutralisation in vitro Moldt B, Rakasz EG, Schultz $\mathrm{N}$, et al. Highly potent $\mathrm{HIV}$-specific antibody neutralisation in vitro
translates into effective protection against mucosal SHIV challenge in vivo. Proc Natl Acad Sci translates into effective protection against mucosal SHIV challenge in

74. Doria-Rose NA, Bhiman JN, Roark RS, et al. New member of the V1V2-directed CAP256-VRC26 lineage that shows increased breadth and exceptional potency. Virology 2015;90(1):76-91. https://doi. org/10.1128/JVI.01791-1

75. Coetzee J, Gray G, Jewkes R. Prevalence and patterns of victimisation and poly-victimisation amongst female sex workers in Soweto, a South African township: A cross-sectional, respondent-driven sampling study. Glob Health Action 2017;10(1):1403815. https://doi.org/10.1080/16549716.2017.1403815

6. Coetzee J, Jewkes R, Gray G. Understanding factors associated with HIV amongst female sex worker in Soweto (poster presentation THPED369). AIDS Conference, Durban, 2016.

77. Huschke S, Coetzee J. Sex work and condom use in Soweto, South Africa: A call for community-based interventions with clients. Culture Health Sexuality 2019;1:1-15. https://doi.org/10.1080/13691058. 019.1568575

78. Milovanovic M, Jaffer M, Mbowane V, et al. Male clients of female sex workers in South Africa: Sexual risk behaviour and violence. SA AIDS Conference, Durban, 2019.

79. Otwombe KN, Dietrich J, Sikkema KJ, et al. Exposure to and experiences of violence among adolescents in lower socio-economic groups in Johannesburg, South Africa. BMC Public Health 2015, 5:450. https://doi.org/10.1186\%2Fs12889-015-1780-8

80. Stone J, Mukandavire C, Boily M-C, et al. Estimating the contribution of key populations towards HIV transmission in South Africa. ICASA Conference, Uganda, 2019.

81. Dunkle K, Jewkes R, Brown H, Gray GE, McIntyre J, Harlow S. Gender-based violence, relationship power and risk of HIV infection in women attending antenatal clinics in South Africa. Lance 2004;363(9419):1415-1421. https://doi.org/10.1016/S0140-6736(04)16098-4

82. Dunkle KL, Jewkes RK, Brown HC, Gray GE, McIntryre JA, Harlow SD. Transactional sex amon women in Soweto, South Africa: Prevalence, risk factors and association with HIV infection. Soc Sc Med 2004;59(8):1581-1592. https://doi.org/10.1016/j.socscimed.2004.02.003

83. Dunkle KL, Jewkes RK, Brown HC, et al. Prevalence and patterns of gender-based violence and revictimisation among women attending antenatal clinics in Soweto, South Africa. Am J Epidemio 2004;160(3):230-239. https://doi.org/10.1093/aje/kwh194

84. Jewkes R, Abrahams N. The epidemiology of rape and sexual coercion in South Africa: An overview. Soc Sci Med 2002;55(7):1231-1244. https://doi.org/10.1016/s0277-9536(01)00242-8

85. Jewkes R, Dunkle K, Koss MP, et al. Rape perpetration by young, rural South African men Prevalence, patterns and risk factors. Soc Sci Med 2006;63(11):2949-2961. https://doi.org/10.1016/j. socscimed.2006.07.027

86. Jewkes R, Dunkle K, Nduna M, et al. Factors associated with HIV sero-status in young rura South African women: connections between intimate partner violence and HIV. Int J Epidemiol 2006;35(6):1461-1468. https://doi.org/10.1093/ije/dyl21

87. Coetzee J, Buckley J, Owtombe K, Milovanovic M, Gray G, Jewkes R. Depression and post-traumatic stress among female sex workers in Soweto, South Africa: A cross-sectional, respondent-driven sample. PloS ONE 2018;13(7):e0196759. https:// doi.org/10.1371\%2Fjournal.pone.0196759

88. Nakimuli-Mpungu E, Bass JK, Alexandre P, et al. Depression, alcohol use and adherence to antiretroviral therapy in sub-Saharan Africa: A systematic review. AIDS Behav 2012;16(8):2101-2118. https://doi.org/10.1007/s10461-011-0087-8

89. Tucker JA, Vuchinich RE, Rippens PD. A factor analytic study of influences on patterns of help-seeking among treated and untreated alcohol dependent persons. J Subst Abuse Treat 2004:26(3):237-242. https://doi.org/10.1016/S0740-5472(03)00209-5

90. Hatcher AM, Smout EM, Turan JM, Christofides N, Stöckl H. Intimate partner violence and engagement in HIV care and treatment among women: A systematic review and meta-analysis. AIDS 2015;29(16):2183-2194. https://doi.org/10.1097/QAD.0000000000000842 